\title{
EL NUDGE, SU APLICACIÓN EN EL DERECHO CHILENO Y SUS POTENCIALES PROBLEMAS DE CONSTITUCIONALIDAD
}

\author{
NUDGE, ITS APPLICATION IN CHILEAN LAW, AND ITS POTENTIAL \\ CONSTITUTIONAL ISSUES
}

\author{
Viviana Ponce de León Solís*
}

\begin{abstract}
RESUMEN: En los últimos años se han incorporado al derecho chileno diversas regulaciones consistentes con la noción doctrinaria de nudge. Dado que estas regulaciones pretenden influir en los sistemas que guían los procesos cognitivos de las personas, la literatura comparada sobre el tópico cuestiona recurrentemente su constitucionalidad, desde la perspectiva de la dignidad humana, la libertad individual, la democracia y el principio de publicidad y transparencia. La idea central de este artículo es que aunque tales cuestionamientos no deben ser menospreciados, ellos no tienen un alcance universal y solo se refieren a categorías específicas de esta especie de regulación. A la luz de esta observación se afirma que no hay nada intrínsecamente ilegítimo en el nudge y se identifican parámetros para evaluar su constitucionalidad.
\end{abstract}

Palabras clave: Nudge, dignidad, libertad individual, democracia, publicidad y transparencia.

ABSTRACT: In the last few years different regulations consistent with the scholarly notion of nudge have been incorporated to Chilean law. Since these regulations aim to influence the systems that guide people's cognitive processes, comparative literature on the subject recurrently questions their constitutionality from the standpoint of human dignity, individual liberty, democracy, and the principle of publicity and transparency. The main idea of this article is that although such questionings should not be overlooked, they do not have a universal scope and only refer to specific categories of this kind of regulation. In light of this observation it is stated that there is nothing intrinsically illegitimate in nudging and it identifies parameters to evaluate their constitutionality.

Keywords: Nudge, autonomy, dignity, individual liberty, democracy, publicity and transparency.

\section{INTRODUCCIÓN}

En los urinales del baño de varones del aeropuerto Amsterdam-Schiphol se encuentra estampada la famosa imagen de una mosca. ¿Su objetivo? Capturar la atención de sus usuarios para que apunten a ella y, de esta manera, se reduzcan las salpicaduras. La medida ha conseguido mantener los sanitarios limpios por más tiempo y disminuir considerablemente los costos de aseo ${ }^{1}$. Por otro lado, en la tienda estadounidense Pay \& Save un grupo de investigadores ubicó flechas verdes grandes y llamativas en el piso, que se dirigían a los

\footnotetext{
* Doctora en Derecho. Profesora de Derecho Constitucional de la Facultad de Ciencias Jurídicas de la Universidad Austral de Chile, Puerto Montt, Chile. Dirección postal: Los Pinos s/n, Balneario Pelluco, Puerto Montt, Chile. Correo electrónico: viviana.poncedeleon@uach.cl.

1 Thaler y Sunstein (2008) p. 261.
} 
pasillos de frutas y verduras. Como resultado, los compradores comenzaron a seguir las flechas y las ventas de frutas y verduras aumentaron significativamente ${ }^{2}$. Asimismo, en un experimento conducido en Noruega durante el año 2012, se disminuyó (en distintas proporciones) el tamaño de los platos utilizados en el buffet de distintos hoteles. En todos los casos, el experimento concluyó consistentemente que la reducción del tamaño de los platos conducía a reducir también la pérdida y el desperdicio de alimentos ${ }^{3}$.

Cada una de estas medidas constituye una ilustración de aquello que en literatura se ha denominado nudge, expresión anglosajona que literalmente se traduce al español como "empujoncito". Con ella se alude a ciertas intervenciones o medidas, públicas o privadas, que se apoyan en las ciencias conductuales, para influir en el comportamiento de las personas -dándoles un empujoncito- en un determinado sentido, pero preservando su libertad de elección. En otras palabras, dichas intervenciones o medidas no reposan en la coacción y, por ende, no mandan ni prohíben. Ellas más bien inciden en el modo en que se organiza y presenta el contexto en el cual las personas toman sus decisiones o, en los términos empleados en la literatura especializada sobre el tópico, en la "arquitectura de decisiones" consecuencia, el nudge se puede definir como "cualquier aspecto de la arquitectura de decisiones que altera el comportamiento de las personas de una manera predecible sin prohibir ninguna opción ni cambiar significativamente sus consecuencias económicas"5.

Durante la última década, estas ideas han tenido un profundo impacto en el ámbito público, particularmente en el diseño de políticas de salud, previsión y preservación del medio ambiente, entre otras. Así, en el año 2010, el Reino Unido fue el primer país en crear un organismo público encargado de incorporar perspectivas conductuales en distintos ámbitos regulatorios (Behavioural Insights Team) ${ }^{6}$. Pronto le siguieron Alemania (2011, Kompetenzcenter Entwicklung, Governance und Frieden) ${ }^{7}$, los Países Bajos (2013, Kenniskamer Gedragswetenschappen) ${ }^{8}$, Estados Unidos (2015, Social and Behavioural Science Team $)^{9}$ y Australia (2016, Behavioural Economics Team of the Australian Government) ${ }^{10}$, entre otros. A ellos se ha sumado un número considerable de entidades privadas, nacionales e internacionales, con y sin fines de lucro, creadas para el mismo propósito ${ }^{11}$.

Chile no ha quedado del todo marginado de esta tendencia y su derecho ofrece una serie de ejemplos de iniciativas que, aun cuando no reciban oficialmente tal denominación, son consistentes con la configuración teórica del nudge. En este contexto, esta investigación tiene por objeto identificar los eventuales ámbitos de contradicción entre dichas iniciativas y la constitución. Para ello, para comenzar, se exponen las ideas claves en que se sustenta la

\footnotetext{
PAYNe (2016).

3 KallbekKen y SÆlen (2013).

Thaler y Sunstein (2008) p. 3.

5 Thaler y Sunstein (2008) p. 6.

6 OECD (2017) p. 23.

OECD (2017) p. 187.

8 Stroeker (2016) p. 28.

9 OECD (2017) p. 109.

10 OECD (2017) 24.

11 OECD (2017) $24 \mathrm{~s}$.
} 
propuesta de una regulación conductualmente informada, las ventajas que se le atribuyen por parte de quienes promueven esta clase de medidas y las características centrales de las mismas. Luego, valiéndose de ejemplos concretos de medidas adoptadas en Chile, se precisan algunas de sus categorías. Finalmente, se pasa sucintamente revista a las principales críticas que se le han formulado, en cuanto menosprecia las preferencias individuales ya formadas, manipula o subvierte los procesos de formación de preferencias y conduce a regulaciones tecnocráticas, invisibles y exentas de control. La idea central que aquí se plantea es que dichas críticas no son predicables respecto del nudge en abstracto, sino que solo valen para ciertos casos en concreto. Con todo, aquellas pueden proveer orientaciones o parámetros para evaluar la constitucionalidad de los nudges existentes o de los que pudieran crearse en el futuro. Finalmente, cabe señalar que esta investigación solo se referirá a los nudges deliberados que resultan de la acción estatal. En consecuencia, quedan excluidos los nudges accidentales o no intencionales, los nudges que operan entre particulares y los counter-nudges o nudges dirigidos a contrarrestar otros nudges.

\section{EL NUDGEY LOS SISTEMAS DE OPERACIONES COGNITIVAS}

El uso de la expresión nudge se ha popularizado en la literatura anglosajona gracias a la obra seminal de Richard Thaler y Cass Sunstein, titulada Nudge: Improving Decisions about Health, Wealth, and Happiness, publicada el año 2008. A pesar del ampliamente difundido uso de dicha expresión en literatura, otras propuestas terminológicas a nivel comparado para referir a estas figuras comprenden la idea de regulación conductualmente informada (behaviorally informed regulation $)^{12}$ o de regulación basada en diseño (design based regulation $)^{13}$. En cualquier caso, todas estas denominaciones aluden a una técnica de regulación cuya eficacia no depende del recurso a la coerción, sino que reposa en la recepción de las contribuciones de la economía conductual y la psicología cognitiva. De singular relevancia resulta en este aspecto la denominada teoría del proceso dual, conforme a la cual es posible distinguir dos sistemas de operaciones cognitivas: el sistema automático o sistema 1 y el sistema reflexivo o sistema $2^{14}$.

El sistema 1 se caracteriza por ser rápido, automático y no consciente ${ }^{15}$. Ello es así porque los procesos cognitivos que caen bajo su dominio son guiados por intuiciones, heurísticas y sesgos que permiten responder velozmente a ciertos estímulos ${ }^{16}$, como cuando esquivamos un objeto que es arrojado en nuestra dirección de imprevisto. Sin embargo,

\footnotetext{
12 Allemano y Spina (2014) p. 431; Barr (2012); Barr, Mullainathan y Shafir (2009); McCrudden y King (2016) p. 82; SUNSTEIN (2013a) p. 73.

13 Yeung (2011); Yeung (2008).

14 Thaler y Sunstein dedican un apartado completo de su libro a la distinción de estos dos sistemas. Cfr. THALER y Sunstein (2008) pp. 19-31. Dicha distinción figura de manera recurrente y prominente en buena parte de las obras posteriores sobre el nudge. Cfr., entre otros, Baldwin (2014); Hansen y Jespersen, (2013) pp. 13 s.; John y Stoker (2017) pp. 14-16; McCrudden y King (2016) p. 77; Sunstein (2106); Sunstein (2015) p. 425; VAN AAKEN (2015).

15 Kahneman (2011) p. 20.

16 En este punto resultó particularmente influyente el trabajo de TVERSKY y KAHNEMAN (1974), sobre los sesgos cognitivos que resultan de apoyarse en heurísticas de juicio. En esta investigación, a vía de ilustración, solo se
} 
esas mismas intuiciones, heurísticas y sesgos pueden conducir de manera predecible a las personas a cometer errores y tomar decisiones sub-óptimas ${ }^{17}$. Así, aquéllas son proclives a preferir las elecciones que producen una recompensa en el corto plazo por sobre aquellas que producen una recompensa a futuro; por ejemplo, al optar entre gastar o ahorrar (sesgo presente $)^{18}$. Igualmente, tienden a creer que tienen menos posibilidades de experimentar un evento negativo -o más de experimentar uno positivo- que el resto; por ejemplo, frente al consumo de productos con potenciales efectos nocivos para la salud (sesgo optimista) ${ }^{19}$. O se ven inclinadas a repetir elecciones previas, con independencia de sus resultados o a preferir el estado actual de las cosas por sobre la posibilidad de cambio; por ejemplo, ante la disyuntiva de mantener o cambiar su plan de salud o previsional (sesgo inercial o sesgo statu quo $)^{20}$.

Por contraste, el sistema 2 se caracteriza por ser lento, controlado y consciente. En consecuencia, los procesos cognitivos que se encuentran bajo su dominio "se suelen asociar con la experiencia subjetiva de agencia, elección y concentración" ${ }^{21}$. Él es activado frente a todas aquellas situaciones para las cuales el sistema 1 no tiene respuesta o para evitar cometer un error y recobrar el control. Bajo su dominio quedan comprendidas todas las operaciones que requieren enfocar la atención, como las operaciones matemáticas y estadísticas, el uso de lenguas distintas a la nativa o el desarrollo de un argumento, por mencionar algunos ejemplos. Si bien este sistema no es infalible, es menos propenso a los sesgos, particularmente a los errores cognitivos ${ }^{22}$. Pese a esta ventaja, el sistema 2 no es eficiente a la hora de tomar decisiones rutinarias, pues estar "constantemente cuestionando nuestro propio pensamiento sería imposiblemente tedioso" 23 .

La distinción entre los sistemas 1 y 2 puede revestir gran utilidad para el derecho. La premisa básica del análisis económico del derecho, según la cual las personas poseen atención y habilidad cognitiva ilimitadas para adoptar decisiones racionales, ha tenido un fuerte impacto en el pensamiento jurídico de los últimos cincuenta años ${ }^{24}$. Sin embargo, bajo el enfoque de las ciencias conductuales esta premisa pasa a ser blanco de serios cuestionamientos, toda vez que pone en evidencia que muchas veces la conducta de las personas es guiada por intuiciones, heurísticas y sesgos inconscientes. En este contexto, dicho enfoque ofrece bases teóricas para el diseño de políticas públicas y regulaciones más eficientes, particularmente en aquellos ámbitos regulatorios que inciden de modo gravitante en las decisiones de las personas sobre cómo vivir su propia vida. Piénsese, por ejemplo, en las políticas de control del tabaquismo, de prevención del sobrepeso y la obesidad, de donación

mencionan tres. Para otras enunciaciones de los mentados sesgos y referencias, véanse AllEMANo y SpINA (2014) p. 431; SunStein (2013b) pp. 1842-1852; Thaler y Sunstein (2008) pp. 31-39.

17 Kahneman (2011) p. 24, Thaler y Sunstein (2008) p. 34; Tversky y Kahneman (1974).

18 SunSTEIN (2013b) pp. 1843-1845.

19 SHAROT (2011).

20 Thaler y Sunstein (2008) p. 34.

21 Kahnemann (2011) p. 21.

22 Kahnemann (2011) p. 28.

23 Kahnemann (2011) p. 28.

24 Barr (2012) p. 442; Barr, Mullainathan y Shafir (2009) p. 27; Jolls, Sunstein y Thaler (1998) pp. 1476-1481. 
y trasplante de órganos, de ahorro previsional, de consumo energético doméstico, de reciclaje, etc. En estos casos, considerando el interés general involucrado, el Estado no puede abstenerse de intervenir sin dejar de cumplir sus deberes. Mas, al efecto, las técnicas tradicionales de regulación basadas en la coacción podrían conllevar una eventual afectación ilegítima a la libertad individual, en tanto que la asignación de incentivos directos podría resultar excesivamente costosa.

De esta manera, el nudge se presenta como una suerte de nuevo paradigma regulatorio, que tendría una serie de ventajas en comparación con los que le han precedido. Así, por un lado, se trataría de una técnica regulatoria de mayor eficiencia, en la medida que conduciría a resultados estadísticamente predecibles en la conducta de los sujetos regulados, con miras a la consecución de fines de interés general y al propio bienestar de estos ${ }^{25}$. Estos resultados podrían obtenerse de dos modos. Una primera alternativa consiste en aprovechar las intuiciones, heurísticas y sesgos propios del sistema 1, a objeto de mantener a las personas en modo automático y lograr que sigan un curso predecible de acción. Otra alternativa es capturar la atención reflexiva de las personas, activando el sistema 2 y promoviendo la adopción de decisiones informadas y deliberadas. Por otro lado, al no privar coactivamente a las personas de la posibilidad de escoger alternativas sub-óptimas de comportamiento ni elevar los costos de las mismas, se preservaría de mejor manera su libertad individual ${ }^{26}$. Ambas ventajas determinarían la adscripción del nudge a la filosofía del "paternalismo libertario", oxímoron acuñado por los propios Thaler y Sunstein ${ }^{27}$. Con él, se busca precisamente enfatizar el atractivo político de esta figura, en cuanto -al menos en la lectura de estos dos autores- aspira a ajustar la conducta individual al efectivo cumplimiento de fines socialmente deseables (paternalismo) y la plena libertad de las personas (libertarismo).

Para estos efectos, los autores que comento sostienen: "[E]l aspecto libertario de nuestras estrategias radica en la convicción de que, en general, las personas deben ser libres para hacer lo que desean, y para desvincularse de los acuerdos desventajosos si lo prefieren" 28 . Asimismo, entienden que una determinada medida es paternalista "si intenta influir en las decisiones de manera que quienes deciden salgan beneficiados, a juicio de ellos mismos" 29 . En otras palabras, esta clase de medidas busca inducir a sus destinatarios a seguir los cursos de acción que presumiblemente adoptarían si prestaran atención, si dispusieran de toda la información, si tuvieran capacidades cognitivas y si tuvieran un autocontrol absoluto $^{30}$. Son dos, entonces, las características distintivas de esta forma de paternalismo: (i) que busca beneficiar a las personas, incentivándoles a tomar decisiones que sean buenas para ellas mismas y (ii) que los destinatarios de la medida estarían de acuerdo con esta evaluación de su decisión ${ }^{31}$.

25 Thaler y Sunstein (2008) p. 7.

26 Thaler y Sunstein (2008) pp. $5 \mathrm{~s}$.

27 Thaler y Sunstein (2008) p. 6.

28 Thaler y Sunstein (2008) p. 5.

29 Thaler y Sunstein (2008) p. 5.

30 Thaler y Sunstein (2008) p. 5.

31 Hausman y Welch (2009) p. 126. 


\section{CLASES DE NUDGES Y SU APLICACIÓN EN EL DERECHO CHILENO}

En la literatura sobre regulaciones conductualmente informadas existe una plétora de propuestas de clasificaciones. El propio Sunstein, sin ir más lejos, identifica hasta diez clases: reglas por defecto, simplificación, uso de normas sociales, incrementos de facilidad y conveniencia, disclosures, advertencias, estrategias de precompromiso, recordatorios, provocar intenciones de implementación y provisión de información a las personas sobre la naturaleza de sus propias elecciones previas ${ }^{32}$. Baldwin, a su turno, distingue entre nudges de primer, segundo y tercer grado, según el nivel de intensidad con que la medida afecta la libertad de la persona cuya decisión se trata de influenciar ${ }^{33}$. Por su parte, van Aaken formula una clasificación entre nudges visibles e invisibles, en atención al grado en el que la medida en cuestión es capaz de satisfacer las exigencias del principio de publicidad y transparencia ${ }^{34}$. Sin perjuicio de estas y otras propuestas adicionales que existen en doctrina, aquí se hará referencia solo a tres clases de nudge: las informaciones, las reglas por defecto y las advertencias gráficas o de otro tipo. La razón por la cual se escogió esta distinción es que con ella se recogen las más prominentes modalidades de nudge existentes en Chile, según se ilustrará con ejemplos. Con todo, es importante destacar que el estudio desarrollado en este apartado no aspira a ser exhaustivo y, por ende, no niega la existencia de otros posibles ejemplos o modalidades de regulaciones conductualmente informadas en el ordenamiento jurídico nacional.

\section{INFORMACIONES}

Una forma muy sencilla de afectar el comportamiento de las personas consiste en simplemente entregarles información acerca de las decisiones a las que se ven enfrentadas. En cuanto a su contenido, la información puede cubrir aspectos muy diversos, como el comportamiento estadístico de otras personas, hitos relevantes en el proceso de toma de decisiones, los costos y beneficios que conlleva cada opción, etc. Por otro lado, en cuanto a su forma, ella puede asumir la forma de recordatorios (como avisos de inicio del plazo para pagar un determinado tributo), de mecanismos de arrepentimiento (como preguntas al estilo de “'está seguro de querer enviar su formulario/solicitud/declaración?” al tomar decisiones relevantes o definitivas en plataformas electrónicas) o de mera provisión de información fáctica (como la indicación de los ingredientes, su proporción y valor nutricional en un determinado producto alimenticio), entre otros.

La iniciativa "Cuentas Claras, Simples y Transparentes"35 es una muestra de esta clase de nudge. Dicha iniciativa, enmarcada en la Agenda de Energía del año 20146 ${ }^{36}$, tenía por objetivo conocer la percepción de la ciudadanía acerca del contenido de las boletas de consumo de gas y electricidad, y así poder introducir mejoras a estas para facilitar su compren-

\footnotetext{
32 SUNSTEIN (2014) pp. 585-587.

33 BALDWIN (2014) p. 835.

34 VAN AAKEN (2015).

35 Laboratorio de Gobierno, SERNAC y SEC (2017).

36 Ministerio de Energía (2014).
} 
sión. Al efecto, se realizó una consulta pública y más de treinta mil encuestas presenciales cuyos resultados fueron analizados por autoridades de la Superintendencia de Electricidad y Combustibles, representantes de empresas eléctricas y de gas y ciudadanos de distintas regiones del país. La información recabada de este modo se tradujo en una serie de propuestas a incorporar en el diseño de las boletas, entre las cuales se incluyeron -solo por mencionar algunas indicaciones- consejos para ahorrar y el historial de consumo de sus destinatarios. El propósito de agregar estas indicaciones en las boletas fue, en particular, "construirlas desde un lenguaje ciudadano y con un formato coherente con aquello que a las personas les interesa saber con mayor prioridad" ${ }^{37}$. Con ello, en definitiva, se otorgaría a los consumidores las herramientas necesarias para propiciar un consumo más eficiente de energía ${ }^{38}$.

El sistema de etiquetado nutricional de los alimentos envasados también queda comprendido dentro de esta categoría de nudge. Dicho sistema se implementó gradualmente en Chile desde del año 1995, comenzando con el etiquetado obligatorio para aquellos alimentos que declararan poseer propiedades nutricionales o saludables (como, por ejemplo: "0\% grasas", "sin azúcar”, "con probióticos”). A partir del año 2005, esta exigencia se hizo extensiva al resto de los alimentos envasados. En términos prácticos, lo dicho implica que debe incluirse en el etiquetado información sobre el aporte de energía, proteínas, hidratos de carbono, grasa, vitaminas o minerales que contiene cada producto alimenticio. Con esta medida, al igual que con la inclusión de advertencias gráficas dispuesta por la Ley No 20.606, sobre composición nutricional de los alimentos y su publicidad ${ }^{39}$, también se pretende influir en las elecciones alimenticias de los consumidores. Sin embargo, la diferencia radica en que en este caso la información provista no busca derechamente incentivar o desincentivar el consumo de determinados productos, sino, en general, promover la adopción de decisiones de consumo informadas en base a las propiedades de dichos productos.

\section{REGLAS POR DEFECTO}

Las reglas por defecto (default rules) corresponden a una categoría de nudge que determina de manera automática el estatuto que se aplicará en un determinado contexto, a menos que su destinatario formule expresamente una opción diversa (opt-out rule). Ellas aprovechan los sesgos preexistentes de las personas, puntualmente el sesgo statu quo o inercial, a fin de orientar sus decisiones en un sentido previsible ${ }^{40}$. Aun cuando en línea de principio una regla de opción activa pueda estimarse más acorde a la noción de libertad, el recurso a esta técnica se justifica en ciertos contextos en los que escoger puede resultar en exceso gravoso y desgastante. Tal puede ser el caso, por ejemplo, de las decisiones que deban efectuarse en el ámbito financiero, previsional o tributario, en especial si se carece de conocimientos especializados sobre el particular. Fuera de esos casos, el uso de reglas por defecto no es en absoluto desconocido para el derecho, como lo revela la multiplicidad de normas supletorias que se contempla en materia contractual, matrimonial y sucesoria, entre otras.

\footnotetext{
37 Laboratorio de Gobierno, SERNAC y SEC (2017) p. 4.

38 Laboratorio de Gobierno, SERNAC y SEC (2017) pp. 20, 25 y 29.

39 LEY No 20.606 de 2012.

40 Sunstein (2008) p. 35.
} 
En Chile, un primer ejemplo de esta clase de nudges es el consentimiento presunto para la donación de órganos, previsto en la Ley No 19.451 que Establece Normas Sobre Trasplante y Donación de Órganos ${ }^{41}$. Originalmente, la ley establecía un sistema de consentimiento expreso, en virtud del cual el donante debía manifestar su voluntad mediante una declaración firmada ante notario o al momento de obtener o renovar la cédula nacional de identidad (art. 90). Con el fin de elevar las tasas de donaciones, la Ley No $20.413^{42}$ introdujo modificaciones a la Ley No 19.451, estableciendo un sistema de consentimiento presunto y conservando la posibilidad de manifestar la renuncia ante el Registro Civil. Dicha manifestación podía hacerse en cualquier momento o al obtener o renovar la cédula de identidad o la licencia de conducir vehículos motorizados (art. único, No 9o). Como consecuencia de esta reforma, las tasas de donación experimentaron una drástica caída ${ }^{43}$. Frente a ello, la Ley No $20.673^{44}$ volvió a introducir una modificación al sistema, manteniendo el consentimiento presunto y la posibilidad de renunciar a él, pero solo mediante manifestación que constara en documentación fidedigna, otorgada ante notario público (art. único, $\mathrm{N}^{\text {os }} 1$, inc. $1^{\circ}$ y $2^{\circ}$, y 2.). Con este nuevo sistema, los donantes de órganos aumentaron en más de un $100 \%$ y el trasplante de órganos en más de un 50\% desde $2010^{45}$.

Un segundo ejemplo corresponde al sistema de cotización previsional obligatoria para trabajadores que emiten boletas de honorarios. El año 2008, la Ley No 20.255 que establece reforma previsional ${ }^{46}$, impuso a los trabajadores independientes la obligación de cotizar. Esta reforma, cuya vigencia inicialmente se extendió entre los años 2012 y 2014, se tradujo en que los trabajadores a honorarios tuvieran que realizar cotizaciones previsionales para pensiones, seguro de accidentes de trabajo y enfermedades profesionales, por un porcentaje de la renta imponible progresivamente mayor, excepto que hubiesen manifestado expresamente su voluntad de no cotizar mediante una declaración jurada en las respectivas operaciones renta 2013, 2014 y 2015. Con posterioridad, la Ley No $20.894^{47}$ prorrogó esta obligación hasta el año 2018, a partir del cual los trabajadores independientes están obligados a cotizar el $100 \%$ de su renta imponible anual, sin posibilidad de renunciar a ello. El sentido de la reforma era permitir a los trabajadores independientes gozar de los mismos derechos y beneficios previsionales que los trabajadores dependientes, cuyas cotizaciones previsionales son retenidas por su empleador.

\section{ADVERTENCIAS GRÁFICAS O TEXTUALES}

Un último tipo de nudge que puede encontrarse en el derecho chileno corresponde a las advertencias gráficas o textuales. Las mismas consisten en signos, imágenes o palabras llamativas que transmiten información acerca de los peligros o riesgos que conlleva una

\footnotetext{
41 LEY No 19.451 de 1996.

42 LEY No 20.413 de 2010.

43 ZÚNIGgA (2015) p. 1332.

${ }^{44}$ LEY No 20.673 de 2013.

45 Zúniga (2015) p. 1333.

46 LeY No 20.255 de 2008.

47 LeY No 20.894 de 2016.
} 
determinada opción. Su propósito es justamente atraer la atención de las personas a los referidos peligros y riesgos, considerando que los mismos podrían ser menospreciados en razón del sesgo optimista. Valga como muestra de lo dicho la utilización de emoticones felices o infelices (representaciones gráficas de rostros sonrientes o ceñudos) en las cuentas de consumo doméstico de electricidad, para expresar el nivel de aceptabilidad social de dicho consumo ${ }^{48}$. Como se puede apreciar a partir de este ejemplo, el rasgo distintivo de las advertencias, en contraste con los nudges de información, es que el arquitecto de opciones no asume una postura neutra frente a su contenido, sino que le asigna una determinada connotación o valoración.

En Chile, esta hipótesis puede ser graficada con las advertencias sanitarias en envases de cigarrillos, previstas en el art. $6^{\circ}$ de la Ley No 19.419, que regula actividades que indica relacionadas con el tabaco ${ }^{49}$. Según esta disposición, "todo envase de productos de tabaco [...] debe contener una clara y precisa advertencia de los daños, enfermedades o efectos que, para la salud de las personas, implica su consumo o exposición al humo del tabaco". Las advertencias, cuyo número puede variar entre dos y seis según lo dispuesto en el respectivo reglamento, pueden ser diseñadas con dibujos, fotografías o leyendas y deben estar siempre a la vista, en todos los puntos de ventas de productos de tabaco. El objetivo de estas medidas es reducir el consumo de tabaco en la población y sobre todo, retardar o inhibir el hábito en los jóvenes, así como fomentar la toma de conciencia en la población acerca de los peligros que encierra el consumo de tabaco. A la fecha, entre las advertencias gráficas se han incluido imágenes de pacientes de cáncer que han perdido su laringe, de cirugías abiertas de tórax, de miembros ulcerados y de infantes conectados a dispositivos de soporte vital, entre otros. Del mismo modo, se han incorporado leyendas como "si fumas, intoxicas a tu hijo/a", "el tabaco te deja impotente", "estos cigarrillos te están matando" o "yo tengo mal aliento".

Como segundo ejemplo puede mencionarse el uso de sellos gráficos de advertencia "alto en" en los alimentos envasados. La medida fue adoptada en virtud de la Ley No 20.606, referida más arriba. De acuerdo con el art. 50 de dicha ley, corresponderá al Ministerio de Salud determinar los alimentos que presenten en su composición nutricional elevados contenidos de calorías, grasas, azúcares o sal. Tales alimentos deben ser rotulados como "alto en calorías", "alto en sal" o con otra denominación equivalente, según el caso. Esta medida está orientada a ayudar a los consumidores a comprender mejor la información nutricional de los alimentos, proteger a los niños de la sobreexposición a la publicidad y, en último término, disminuir las elevadas tasas de obesidad y sobrepeso en Chile ${ }^{50}$. Más concretamente, mediante el impacto visual de los sellos, se pretende influir en las elecciones alimenticias de las personas, incentivando el consumo de alimentos saludables y desincentivando el consumo de alimentos con exceso de calorías o nutrientes críticos.

\footnotetext{
48 SCHultz et al. (2007).

49 LEY No 19.419 de 1995.

50 Proyecto de ley sobre regulación de alimentos poco saludables, Boletín N4.921-11, p. 2.
} 


\section{PERSPECTIVAS CRÍTICAS}

No obstante el avivado interés y entusiasmo que suscita el nudge en ciertos círculos académicos y políticos, existen severas críticas a esta figura. Para algunos, según se expone en este apartado, detrás de la atractiva promesa de una combinación óptima de eficacia y libertad se esconde la amenaza de menosprecio por las preferencias individuales ya formadas, manipulación en el proceso de formación de preferencias y de invisibilización del actuar estatal. De llegar a materializarse dicha amenaza, podrían comprometerse seriamente una serie de valores constitucionales, a saber: la libertad individual, la dignidad humana, la democracia y la publicidad y transparencia. Así pues, de cara a estas críticas, esta parte de la investigación no asume derechamente una postura unitaria de adhesión o de refutación. Antes bien, su sentido es demostrar que, por más atendibles y reales que aquéllas puedan ser bajo ciertos supuestos, no son predicables de manera universal a todos los nudges. Hecha tal demostración, podría afirmarse que la regulación conductualmente informada no es intrínsecamente ilegítima y podrían identificarse parámetros o estándares genéricos que permitan evaluar, para cada regulación en concreto, su constitucionalidad.

\section{MENOSPRECIO POR LAS PREFERENCIAS INDIVIDUALES YA FORMADAS}

Una de las principales objeciones que se esgrime contra el nudge se relaciona directamente con el carácter paternalista -libertario, recuérdese- que Thaler y Sunstein le atribuyen y con su impacto en la libertad individual. Ahora bien, para comprender estas objeciones, es necesaria una breve referencia al concepto de paternalismo. Las definiciones estándar de paternalismo se articulan en torno a tres elementos: (i) la interferencia o limitación a la libertad o decisiones de una persona; (ii) que se realiza contra la voluntad, sin el consentimiento o en forma contraria a las preferencias de esta última; (iii) para su propio bien ${ }^{51}$. Por contraste, el paternalismo libertario se caracterizaría por "corregir bien conocidos sesgos conductuales o errores volitivos, minimizando así la posibilidad de que las personas tomen decisiones que sean contrarias a sus propios intereses" 52 . Es así como esta filosofía "ofrece un posible contra ejemplo a la afirmación de que el paternalismo interfiere con la libertad" $"$ 33.

Sin perjuicio de lo anterior, subsiste un cuestionamiento a la orientación del nudge a la satisfacción del interés de sus destinatarios, puesto que para determinar si ese interés ha sido satisfecho emplea el estándar de "a juicio de ellos mismos". El cuestionamiento surge en atención a que las preferencias de las personas pueden ser tan heterogéneas que dicho estándar, concebido teóricamente en términos subjetivos ${ }^{54}$, puede terminar diluyéndose en una definición estatal objetiva del bienestar personal ${ }^{55}$. Así, estas regulaciones podrían servir como herramientas para orientar decisiciones que en principio parecen estrictamente

\footnotetext{
51 SCOCCIA (2018) p. 11.

52 HUSAK (2015) p. 468.

53 HUSAK (2015) p. 468.

54 Sunstein (2015) p. 430.

55 Allemano y Spina (2014) p. 446.
} 
personales, como qué comer ${ }^{56}$, cuáles hábitos cultivar $^{57}$ y cuáles desechar ${ }^{58}$. A tal extremo llega la preocupación de algunos académicos ante el prospecto de una mala utilización de estas herramientas, que incluso lo comparan con el escenario distópico imaginado por Aldous Huxley en su conocida obra de 1932, Un mundo feliz ${ }^{59}$.

El punto reviste un incuestionable interés para el derecho constitucional. A él subyace la pregunta acerca de si la libertad individual cubre la adopción de decisiones ajustadas a las preferencias de su autor y a la visión personal que este tiene de su propio bienestar, pero desorientadas, equivocadas o irracionales a juicio de terceros ${ }^{60}$. De responderse de manera negativa a esa pregunta, quedaría en entredicho uno de los principios básicos de la dignidad según el cual cada persona es capaz de definir los fines que considera deseables para su pleno desarrollo y las conductas necesarias para alcanzarlos ${ }^{61}$. Lo anterior, a su turno, implicaría asumir que las personas carecen de auto-control, que son incapaces de satisfacer las exigencias de la razón moral y, en definitiva, que no pueden hacerse responsables por sus propias vidas $^{62}$.

Frente a las críticas recién apuntadas es necesario clarificar que no toda regulación conductualmente informada debe ajustarse a la visión de Thaler y Sunstein. Por ende, no requiere adscribir a la filosofía del paternalismo libertario, ni ser paternalista en absoluto ${ }^{63}$. De hecho, algunas de las críticas hechas al carácter paternalista del nudge en este contexto parecen asumir -artificiosamente, a mi juicio- una división estricta y excluyente entre el bienestar personal y el interés general. Piénsese, por ejemplo, en el consumo de productos de tabaco o de alimentos altos en azúcar, grasa o sodio. Difícilmente se puede sostener que se trate de decisiones que solo comprometen el interés personal de quien la adopta, si se consideran las elevadas tasas de patologías asociadas a tales decisiones y los significativos

56 Valga como muestra el establecimiento de un día de alimentación exclusivamente vegana o vegetariana en las cafeterías de establecimientos educacionales públicos. La medida fue implementada en el distrito escolar de Helsinki, Finlandia, desde el año 2007. Su objetivo fue incrementar el consumo de vegetales y presentar nuevos alimentos y sabores a los alumnos. Cfr. Lombardini y LANKOSKI (2013).

57 Por ejemplo, mediante las reglas por defecto que incentivan el ahorro personal.

58 Tal como lo demuestra el caso de las advertencias en las cajetillas de cigarrillos.

59 Cassesse (2016) p. 245; van AaKen (2015) p. 123; Yeung (2011).

60 Sobre el particular se ha sostenido que la libertad es neutral de cara a una específica idea de una "buena vida". Antes bien, su objetivo es proteger la libertad de las personas para formarse su propia concepción de la "buena vida" y les garantiza espacio para hacer sus propias elecciones Cfr. VAN AAKEN (2015) pp. 105 s. Esta idea constituye una de las premisas básicas en que se sustenta el pensamiento liberal, como lo revelan MiLL (2001) p. 13 y BERLin (2013) pp. 178-181.

61 Particularmente en la concepción de la dignidad de Dworkin, para quien el segundo principio de la dignidad es la autenticidad, entendida como la contrapartida del primer principio, que es el auto-respeto. Según esta concepción, el juicio acerca de lo que significa vivir bien implica expresarse a sí mismo en la vida, buscando una forma de vivir que les genere la convicción de ser correctas para sí y para sus circunstancias. Dworkin (2011) p. 209.

62 Goodwin (2016) p. 285. El problema estribaría en la eliminación de las señales normativas que envían las técnicas tradicionales de regulación respecto de la naturaleza moral de las acciones a que ellas se refieren y, como consecuencia de ello, la reducción de las posibilidades de actuar sobre la base de la razón moral. BROWNSWORD (2016) pp. 355-358. De lo anterior se seguiría "un riesgo de que las precondiciones para el debate y discurso moral sean corrompidas y comprometidas". BROWNSWORD (2008) p. 47.

63 John y STOKer (2017) p. 12; Waldron (2014). 
costos que ello impone al sistema público de salud ${ }^{64}$. Resulta evidente a partir de estos supuestos que muchas de las decisiones que las personas adoptan no solo les afectan a ellas, sino que generan externalidades negativas para la comunidad en que viven ${ }^{65}$.

\section{MANIPULACIÓN Y SUBVERSIÓN DEL PROCESO DE FORMACIÓN DE PREFERENCIAS}

Pese al supuesto carácter libertario que se atribuye al nudge, se ha controvertido la idea de que el mismo no interfiera con la libertad individual de las personas. Sin duda, es posible que aquél sea utilizado para alterar, o derechamente construir, las preferencias de estas, lo cual conllevaría el riesgo de bloquear o comprometer su capacidad para considerar de otras opciones y de actuar de acuerdo con las propias preferencias. En este sentido, la regulación conductualmente informada plantea el peligro de que las personas actúen guiadas por las preferencias de los arquitectos de opciones y no las propias, situación que alguna literatura equipara a una manipulación ${ }^{66}$. En tales casos, aunque formalmente no se limiten las opciones de una persona y se preserve su libertad de elección, la medida sería manipuladora pues "pervierte el modo en que esa persona alcanza sus decisiones, forma sus preferencias o adopta metas" ${ }^{\$ 7}$. Ello, a su vez, sería inconsistente con la concepción kantiana de la dignidad, que exige actuar de modo que siempre se trate a la humanidad, ya sea en su propia persona o en la persona de otro, como un fin y jamás como un simple medio ${ }^{68}$.

Ahora bien, lo dicho no implica que todo nudge sea intrínsecamente manipulador. Algunos pueden serlo, pero otros son consistentes con los valores de dignidad humana y libertad individual. Para justificar esta afirmación, puede ser útil distinguir según el tipo de nudge de que se trate, según se expone a continuación.

(i) La información, en exceso, ciertamente puede resultar abrumadora y entorpecer los procesos de adopción de decisiones ${ }^{69}$. Además, su contenido puede ser presentado de un modo sesgado, con el fin de inclinar sistemáticamente las decisiones en un determinado

${ }^{64}$ McCrudden y King (2016) p. 91; SChWeizer (2016) pp. 102-106; Yeung (2012) p. 124.

${ }_{65}$ Con esto no quiero sugerir que no existan en absoluto supuestos en que se presente una contradicción entre el interés general y la definición individual de lo que constituye el bienestar personal. Antes bien, busco exponer que los ejemplos de nudge que alguna literatura considera como representativos de tal contradicción (como los que versan sobre el consumo de productos de tabaco o alimentos altos en azúcar, grasa o sodio) realmente no lo son. Ahora bien, de darse un supuesto de efectiva contradicción, habrá que determinar si la limitación a la libertad que deriva de la imposición del nudge en cuestión se funda en la protección de terceros o de la sociedad. Sobre este posible criterio de legitimación del nudge, véase más abajo el apartado V.1 de esta investigación. ${ }^{66}$ Baldwin (2014) pp. 836 s.; Bovens (2009) p. 208; Hausman y Welch (2010) p. 128; John y Stoker (2017) p. 12; McCrudden y King (2016) pp. 104-111; WaLdron (2014); van Aaken (2015) p. 108, aunque en específica referencia a los nudges que inciden en el sistema 1; WiLKInson (2013) p. 354; Yeung (2012) p. 136.

${ }^{67}$ Raz (1988) p. 377. Otras definiciones en sentido similar pueden verse en Wood (2014) p. 35 y Sunstein (2015) pp. $443 \mathrm{~s}$.

${ }^{68}$ Tal concepción se desprende de la siguiente formulación del imperativo categórico: "[a]ct so that you use humanity, as much in your own person as in the person of every other, always at the same time as end and never merely as means". KANT (2002) pp. $46 \mathrm{~s}$. En otro pasaje de la misma obra el autor complementa esta idea con la de un valor intrínseco que no tiene precio: "[i]n the realm of ends everything has either a price or a dignity. What has a price is such that something else can also be put in its place as its equivalent; by contrast, that which is elevated above all price, and admits of no equivalent, has a dignity". KANT (2002) p. 52.

69 Sunstein (2016) p. 129, n. 33. 
sentido, como lo revela el framing o el encuadre estratégico de información ${ }^{70}$. Por lo demás, ese contenido también puede ser presentado veladamente, siendo el uso de publicidad subliminal un ejemplo recurrente -aunque ( ¿al parecer?) hipotético- de este supuesto ${ }^{71}$. Sin embargo, en muchos otros casos, la información puede corregir errores cognitivos, fomentando la capacidad de las personas para adoptar decisiones racionales, deliberadas y conscientes, de acuerdo con sus genuinas preferencias. Así, ella puede alentar los procesos de decisión reflexivos propios del sistema 2, y evitar que estos caigan irremediablemente en el dominio de lo automático o del sistema 1. De ahí que se afirme que este tipo de nudge puede tener efectos educativos que promueven la libertad individual ${ }^{72}$.

(ii) Por su parte, las reglas por defecto podrían estimarse manipuladoras en cuanto se apoyan en las respuestas automáticas propias del sistema 1, lo cual posibilita que sus destinatarios las acepten de modo inconsciente e irreflexivo ${ }^{73}$. Como se recordará, las reglas por defecto suelen aprovecharse del sesgo statu quo o inercial, explotando la tendencia de las personas a preferir el actual estado de cosas. La opción que se propone por defecto (considerada como socialmente deseable) es la que requiere menos esfuerzo para su adopción, en términos de tiempo y de información. Por contraste, la opción que supone una innovación (considerada como socialmente menos deseable) exige algo más de esfuerzo para su adopción y, por tanto, estadísticamente tiende a ser evitada ${ }^{74}$. En este contexto, para que un nudge fuese considerado no manipulador, tendría que ser diseñado de un modo tal que permita a su destinatario tomar consciencia del mismo, reflexionar sobre su alcance e impacto y, en definitiva, escapar de su aplicación si así lo desea. Asimismo, un nudge podría estimarse no manipulador si de algún otro modo logra optimizar la libre adopción de decisiones de las personas ${ }^{75}$.

(iii) Respecto de las advertencias gráficas o textuales, ellas podrían ser usadas para generar en sus destinatarios una fuerte reacción emocional que, a su vez, inhiba la reflexión y les disuada de seguir adelante con su curso de acción preferido. Piénsese, por ejemplo, en las siguientes advertencias: "estos cigarrillos te están matando" o "si fumas, intoxicas a tu hijo/a". Es discutible si esta clase de nudge conduce a la adopción de decisiones deliberadas, conscientes y acordes con las genuinas preferencias de quien las formula o si, por el contrario, conduce a la adopción de decisiones basadas en el solo temor a ser ridiculizado

\footnotetext{
70 El framing supone la provisión de información de manera tal que influya, en algún sentido predefinido, en las decisiones de las personas. Así, por ejemplo, decir que un producto tiene " $10 \%$ de grasa" no tiene el mismo impacto que decir que es " $90 \%$ libre de grasa". Del mismo modo, decir que el consumo de determinados productos "incrementa de un 0,01\% al 0,03\%" las posibilidades de sufrir un determinado trastorno tampoco tiene el mismo impacto que decir que su consumo lo "incrementa en un $300 \%$ ".

71 Baldwin (2014) p. 837, n. 25; Bovens (2009) pp. 216 s.; Hansen y Jespersen (2013) pp. 16, 17, 23 y 26; Hausman y Welch (2010) pp. 131 s.; McCrudden y King (2016) p. 108; Schweizer (2016) p. 99; Yeung (2012) pp. 143 s.

72 McCrudden y King (2016) p. 111; Sunstein (2016) pp. 124 s.; Sunstein (2015) pp. 427; van Aaken (2015) p. 110.

73 Allemano y Sina (2014) pp. 439; Baldwin (2014) pp. 835 s.; Yeung (2012) p. 130. Adhiere a esta posición, pero solo respecto de las reglas por defecto invisibles, VAN AAKEN (2015) p. 110.

74 Kahneman y Thaler (2012) pp. 348-349.

75 Véase más abajo en esta investigación el apartado V.2.
} 
o marginado y no en las verdaderas preferencias personales ${ }^{76}$. Habida cuenta de que estas medidas podrían no respetar suficientemente las capacidades de adopción de decisiones de las personas e intentan subvertir sus preferencias, ellas podrían estimarse manipuladoras. Sin embargo, lo anterior no significa que cualquier advertencia sea intrínsecamente manipuladora. De hecho, bajo ciertas condiciones, las advertencias podrían contribuir a poner de relieve y visibilizar los reales riesgos que implica una determinada decisión, corrigiendo el sesgo optimista y activando los procesos cognitivos dominados por el sistema $2^{77}$.

\section{TECNOCRACIA, INVISIBILIDAD Y AUSENCIA DE CONTROL}

Frente a las críticas apuntadas cabría preguntarse si las mismas son válidas también para las técnicas tradicionales de regulación basadas en la coacción, esto es, para los mandatos y las prohibiciones. Estas últimas también suponen algún grado de afectación de la libertad individual y las preferencias de las personas -incluso más intenso que el que suponen las políticas de nudge- para la consecución de fines de interés general. Si en los Estados liberales ellas han sido aceptadas, ¿no sería incoherente rechazar los nudges? Quienes han intentado responder a esta interrogante, hacen presente que existiría una gran diferencia entre estos y las prohibiciones, los mandatos y los incentivos directos. En efecto, los últimos siempre son visibles o perceptibles y, por tanto, pueden ser fácilmente identificados por sus destinatarios y, eventualmente, impugnados en cuanto a su constitucionalidad o a su legalidad. Los primeros, en cambio, no siempre son claramente visibles o perceptibles, lo cual hace que sea más difícil tomar consciencia de su existencia e impugnar su aplicación ${ }^{78}$.

Se sigue de lo dicho que más que un cuestionamiento general a esta técnica de regulación en sí misma, hay un cuestionamiento frente a la posibilidad de que ella no satisfaga las exigencias de los principios de publicidad y transparencia. El problema se ve agravado por el hecho de que, en algunos casos, esta clase de medidas, puede ser adoptada mediante intervenciones administrativo-tecnocráticas que no son públicas ni se encuentran abiertas a la deliberación democrática ${ }^{79}$. Piénsese, por vía ejemplar, en el diseño de un recinto público cuya entrada principal conduce directamente a las escaleras tradicionales, en lugar de los ascensores o de las escaleras mecánicas, para incentivar la actividad física de sus usuarios ${ }^{80}$. Refleja asimismo esta hipótesis la disposición de líneas en una carretera de modo tal que estas generen la ilusión óptica de incremento de la velocidad, para inducir a los conductores a manejar más despacio ${ }^{81}$. En ambos casos, no solo el nudge mismo es invisible o imperceptible para el ciudadano promedio, sino que además lo es el procedimiento para su adopción.

Bajo este respecto, la adopción de nudges pone en cuestión uno de los aspectos clave del principio democrático: el control del $\operatorname{poder}^{82}$. Efectivamente, la democracia parece ser

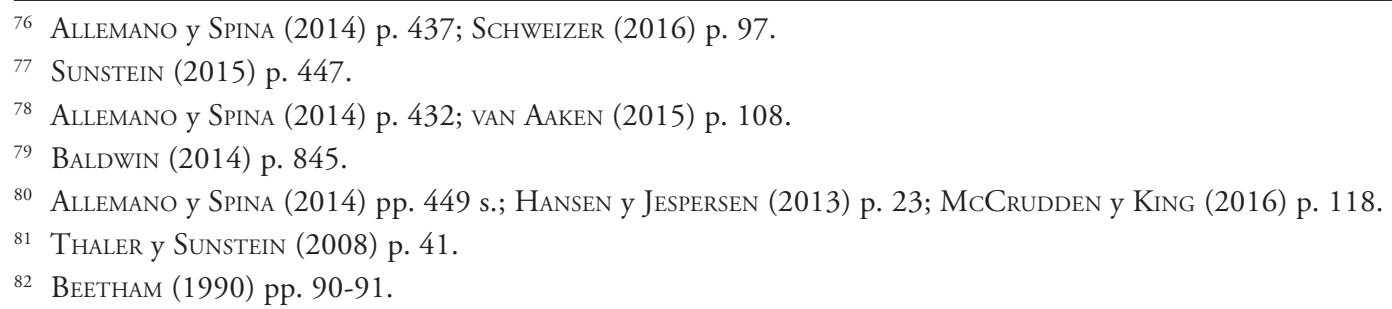


la única forma de gobierno capaz de conciliar adecuadamente la libertad individual con la coerción estatal. En ella, cada individuo interviene con su voluntad, ejerciendo de forma igualitaria su justa cuota de influencia en el proceso político dirigido a la definición del interés general de la comunidad y de las conductas más idóneas para alcanzarlo ${ }^{83}$. Esa intervención individual no solo permite justificar teóricamente el recurso a la coerción estatal, sino que además hace posible el control de las decisiones de la mayoría y determinan su dirección en orden a la promoción de determinados intereses ${ }^{84}$. La preocupación, entonces, es que por la vía de los nudges unos terminen imponiendo su voluntad sobre otros, de manera que los últimos queden sometidos a un poder que no pueden controlar.

En cualquier caso, tampoco puede darse por establecida una incompatibilidad intrínseca entre esta clase de regulaciones, por un lado, y los principios democrático y de publicidad y transparencia, por el otro. El ejemplo chileno demuestra que no hay impedimento alguno para que determinados nudges se adopten mediante procedimientos democráticos. Por otro lado, aún cuando se les adopte a través de intervenciones de índole administrativa, tal circunstancia no exime a la autoridad del deber de hacer posible un efectivo control de su acción.

\section{PROYECCIONES AL CASO CHILENO}

Una vez enunciadas las principales críticas que se formulan al nudge en teoría, y en el entendido de que ellas no tienen un carácter absoluto, es posible identificar las condiciones bajo las cuales estas figuras podrían estimarse legítimas en la práctica. En otras palabras, las posturas críticas que en literatura se formulan frente al nudge permiten deducir ciertos criterios conforme a los cuales se podría juzgar su constitucionalidad. Así las cosas, en este apartado se definirán los parámetros que permitirían establecer que una regulación conductualmente informada no es paternalista, no es manipuladora y no es puramente tecnocrática y carente de publicidad y transparencia. Tales criterios corresponden a su orientación a fines de interés general, su potencial para promover la libre adopción de decisiones y su observancia de las exigencias del principio democrático y de publicidad y transparencia.

\section{ORIENTACIÓN A FINES DE INTERÉS GENERAL Y NO PURAMENTE PATERNALISTAS}

En principio, podría pensarse que el nudge es siempre menos lesivo que otras formas de regulación tradicionales, en cuanto formalmente preserva la libertad de las personas para elegir las conductas que estimen conducentes a su desarrollo personal, sin prohibir o imponer. Si ello fuera efectivo, aquél siempre debería ser preferido antes que cualquier otra técnica de regulación. Mas, desde otra perspectiva, el nudge también puede ser visto como más lesivo, toda vez que altera los contextos en los cuales las personas toman sus decisiones, induciéndoles a tomar cursos de acción que no necesariamente se ajustan a sus genuinas

\footnotetext{
${ }^{83}$ A nivel positivo, este planteamiento encuentra asidero en los artículos $8^{\circ}$ inc. $2^{\circ}$ y 19 Nos. 16 inc. $3^{\circ}, 21$ inc. $1^{\circ}$ y 24 inc. $2^{\circ}$ y $3^{\circ} \mathrm{CPR}$. Todas estas disposiciones aluden a diversas formas de afectación de derechos que se fundan en el "interés nacional”, los “intereses generales de la nación” u otra fórmula análoga. A su vez, cada una de dichas disposiciones entrega la calificación de tal fundamento al legislador.

84 Petit (2012) pp. 239-292; Schmidt (2017) pp. 411-413.
} 
preferencias. Ante estas consideraciones aparentemente discordantes, corresponde dilucidar si existe un deber estatal de respetar las preferencias personales de los individuos y de permitir que estas se formen de manera libre, esto es, sin injerencia de la autoridad. Y, de ser así, corresponde asimismo determinar cuál sería el fundamento de tal deber en el ordenamiento jurídico chileno.

Respecto de este punto, alguna doctrina nacional minoritaria coincide en cuanto a que el referido deber existe, al menos teóricamente. Por ejemplo, Nogueira sostiene que "[l]os ámbitos de la dignidad humana que deben asumirse aplicando la pauta normativa de nuestro artículo $1^{\circ}$, inciso $1^{\circ}$, de la Carta Fundamental son las dimensiones ontológicas dadas por la racionalidad y libertad del ser humano (autodeterminación consciente y responsable de su propia vida), como asimismo la de carácter ético o deontológico constituida por la autonomía y el ser un fin en sí mismo, y no un medio o instrumento de nadie" 85 . Vivanco, a su turno, indica que "la organización política se encontrará impedida de legislar respecto de las consciencias de los individuos, y no podrá perseguirlos por sus opiniones ni forzarlos a suscribir normas morales que no comparten. Se salvaguardarían así la libertad y la dignidad de las personas, ya que bajo este prisma talvez [sic], el componente más relevante de aquellos que conforman el trato digno para con el individuo de la especie humana está constituido por la igualdad en la libertad, [...] que significa ser libre para pensar y actuar de acuerdo al pensamiento propio" ${ }^{86}$. En concordancia con lo anterior, Aldunate señala que pretender asegurar un derecho contra las decisiones de su titular sobre su ejercicio supone que "el individuo deja de ser señor del orden de su prioridades éticas, y pasa a regir sobre ese orden el órgano estatal que decidirá sobre ellos [...]. Ello implica que se priva a la persona de su facultad de autodeterminación ética, misma que es uno de elementos constitutivos de la dignidad de la persona" ${ }^{87}$.

A nivel positivo, el referido deber podría apoyarse en dos disposiciones del texto constitucional. Por un lado, el art. $1^{\circ}$ inc. $1^{\circ} \mathrm{CPR}$ establece que "[l] as personas nacen libres e iguales en dignidad y derechos". Por el otro, el art. 19 No 7 inc. $1^{\circ}$ CPR establece que "[l] a Constitución asegura a todas las personas: [...] [e]l derecho a la libertad personal y a la seguridad individual”. Esta libertad no solo cubriría las concretas proyecciones de su ejercicio que expresamente contempla el art. 19 CPR (ambulatoria, de conciencia, de enseñanza, de emitir opinión e informar, etc.), sino que permitiría hacer todo aquello que no daña a la sociedad o a los derechos de otros. Tal interpretación, que históricamente puede sustentarse en los arts. $4^{\circ}$ y $5^{\circ}$ de la Declaración de los Derechos del Hombre y del Ciudadano ${ }^{88}$, también

\footnotetext{
85 Nogueira (2010) p. 82.

86 Vivanco (2006) pp. $44 \mathrm{~s}$.

87 Aldunate (2008) pp. $162 \mathrm{~s}$.

${ }^{88}$ De acuerdo con la primera de dichas disposiciones, "[l]a libertad consiste en poder hacer todo aquello que no daña a otro: por tanto, el ejercicio de los derechos naturales del hombre no tiene otros límites que aquellos que aseguren a los demás miembros de la sociedad el goce de los mismos derechos. Estos límites solo pueden ser determinados por la ley". La segunda, por su lado, establece que "[1] a ley no tiene el derecho de prohibir sino las acciones nocivas a la sociedad. Todo lo que no está vedado por la ley no puede ser impedido, y nadie puede ser constreñido a ejecutar lo que ella no ordena". A nivel jurisprudencial, esta postura puede verse el siguiente pasaje de un voto particular de una sentencia del Tribunal Constitucional chileno: "el artículo $19 \mathrm{~N}^{\circ} 7^{\circ}$ se vincula directamente con el artículo 4 de la Declaración de Derechos del Hombre y del Ciudadano de 1789, en
} 
ha sido sostenida por algún sector de la doctrina nacional ${ }^{89}$. Así, Nogueira ha señalado que "[1] a libertad personal se refiere a la libertad de la persona física en cuanto ser corporal en sí mismo, constituyendo un derecho matriz y residual, ya que protege las expresiones de libertad no asegurados específicamente por los demás derechos autónomos, lo que posibilita realizar todo aquello que es lícito; es el derecho de toda persona a que los poderes públicos y terceros no interfieran en la esfera de autonomía personal, vale decir, de disponer de su propia persona y de actuar determinado por la propia voluntad sin otras limitaciones que las que imponen el medio natural, los derechos de los demás y el ordenamiento constitucional" $"$.

De aceptarse la concepción de libertad individual aquí propuesta, se seguiría que la misma no es absoluta y admite límites. No obstante, esos límites no pueden sustentarse en motivos puramente paternalistas, como la mera inmoralidad (a juicio de la autoridad) o el posible daño que una persona pudiera infligirse a sí misma. Antes bien, deben sustentarse en el daño a terceros o a la sociedad que resulta de la conducta regulada. La razón para ello radica en que el despliegue de la capacidad humana de autodeterminación posee un valor intrínseco, en cuanto permite a las personas cultivar y ejercitar su su libertad moral ${ }^{91}$. Si el Estado interviene en esa libertad, les despoja de su capacidad para tomar sus propias decisiones, socavando su habilidad para aprender de sus errores y desarrollarse como ciudadanos moralmente responsables ${ }^{92}$.

Lo anterior plantea un problema por cuanto prácticamente toda conducta que causa daño a su autor es susceptible de dañar a otros, aunque sea de manera indirecta y remota ${ }^{93}$. Así, mientras más indirecto y remoto sea el daño a terceros que se trata de precaver mediante la creación de un nudge, mayor será el estándar que deba superar la autoridad para justificar la legitimidad del fin perseguido, en el marco del test de razonabilidad. Por el contrario, mientras más directo y próximo sea el daño, menor será el aludido estándar. En este mismo sentido, es lógico suponer que el estándar de justificación será menor tratándose de fines que se puedan vincular inmediatamente con el cumplimiento de deberes estatales, como los previstos en los arts. $1^{\circ}$ inc. $5^{\circ}$ y $5^{\circ}$ inc. $2^{\circ} \mathrm{CPR}$. En cambio, es de suponer que el estándar de justificación aumentaría si la medida se fundara en una referencia genérica e indeterminada al bien común o al interés general.

cuya virtud 'la libertad consiste en poder hacer todo lo que no daña a los demás'. A ello, su artículo 5 agrega que 'la ley no puede prohibir más que las acciones dañosas para la sociedad. ¿Por qué se emparentan estas normas? Por dos razones. Porque no es razonable la inexistencia de una norma constitucional que garantice la autodeterminación personal que sostiene todo el andamiaje de las libertades personales y públicas. Y, por otro lado, porque la regla del límite de las libertades en torno al daño a los demás está expresamente presente en el artículo $19 \mathrm{~N}^{\circ} 7^{\circ}$, letra a), esto es, quedando a 'salvo siempre el perjuicio de terceros'”. STC, Rol № 1881, artículo 102 del Código Civil, voto particular concurrente de la Ministra Marisol Peña Torres, $31^{\circ}$.

89 Para un completo estudio del estado de la cuestión a nivel nacional, de acuerdo con el cual la posición aquí sostenida corresponde a la de la doctrina y jurisprudencia minoritaria en Chile, véase PARDO (2013).

90 Nogueira (2002) p. 162. La misma idea puede encontrarse también en Nogueira (2003) p. 34; VIVANCO (2006) p. 43.

91 Baldwin (2014) p. 851; Thomas y Buckmaster (2010) p. 7; Sunstein (2015) p. 436; van Aaken (2015) p. 109.

92 Bovens (2009) p. 11; Brownsword (2014) pp. 17-20; Thomas y BucKmaster (2010) p. 7.

93 Schweizer (2016) pp. 103-106; Thomas y Buckmaster (2010) p. 9. 


\section{PROMOCIÓN DE LA LIBRE ADOPCIÓN DE DECISIONES}

Lo hasta aquí expuesto sugiere que podría haber una incompatibilidad entre el nudge, la dignidad humana y la libertad individual, si es que aquél persigue subvertir las verdaderas preferencias de las personas, en lugar de contribuir a su consecución. Pues bien, dado que la adopción de nudges puede conllevar afectación de valores constitucionales y de derechos fundamentales, la misma puede dar lugar a cuestionamientos en cuanto a su constitucionalidad. Al efecto, uno de los estándares preponderantes está representado por el test de proporcionalidad, construcción teórica dirigida a determinar la legitimidad de las afectaciones a los derechos fundamentales ${ }^{94}$. En este punto, puede ser útil la distinción entre nudges educativos -que apelan al sistema 2 y fomentan las decisiones conscientes racionales e informadas- y nudges no educativos -que explotan errores y sesgos cognitivos propios del sistema 1. A su vez, para determinar si un nudge pertenece a una u otra categoría, es necesario hacer una distinción preliminar entre a la modalidad que el mismo asuma, según se explica en las líneas que siguen.

(i) En el caso de la información, esta suele ser vista como una forma relativamente inocua de nudge, puesto que involucra el sistema reflexivo de una manera que facilita a la persona la reconstrucción de las intenciones y los medios por los cuales se busca el cambio conductual $^{95}$. Ahora bien, para que ello efectivamente ocurra, una primera exigencia es que la información sea veraz. La provisión de información falsa con vistas a influir en las decisiones de las personas constituye un engaño y debe ser denunciada como un acto de manipulación ${ }^{96}$. Asimismo, la información debe ser tan neutra y completa como sea posible ${ }^{97}$. El framing y la difusión selectiva de antecedentes también pueden contar como manipulación, en cuanto tienen por objetivo subvertir el proceso de toma de decisiones, exagerando $u$ ocultando datos relevantes para advertir o entender las opciones en juego ${ }^{98}$. Por último, la

\footnotetext{
${ }^{94}$ La literatura sobre el principio de proporcionalidad es prácticamente infinita y su análisis exhaustivo excede con creces los propósitos de la presente investigación. Sin perjuicio de lo anterior, cabe tener presente tres cuestiones. Primero, que la doctrina nacional entiende que el Tribunal Constitucional chileno ha acogido y aplica el principio de proporcionalidad. Segundo, que la doctrina nacional mayoritariamente adhiere a la versión alemana del test de proporcionalidad en sus tres conocidas etapas (idoneidad o adecuación, necesidad y proporcionalidad en sentido estricto) y que, por lo mismo, a esa versión adhiere este texto. Y, tercero, que esa versión admite críticas severas. Sobre las dos primeras cuestiones, véanse Aldunate (2008), pp. 264-267; Arnold, MarTíneZ y ZúNiga (2012) pp. 65-116; DíAZ (2011), pp. 167-206. Respecto de la tercera cuestión, consúltense CONTESSE (2017) pp. 310316 y Covarrubias (2014). Respecto de la aplicación específica de este test al nudge a nivel comparado, véanse McCrudden y King (2016) pp. 128-130; SChWeITZer (2016); VAN AAKen (2015) p. 117-122.

95 Hansen y Jespersen (2013) p. 23; Sunstein (2016).

96 Thaler y Sunstein (2008) p. 245; Wilkinson (2003) p. 5; Yeung (2012) p. 148.

${ }^{97}$ Los propios Thaler y Sunstein admiten que una de las principales lecciones de la psicología es que es imposible una neutralidad absoluta o ideal en la provisión de información y que los contextos en que esta se presenta siempre influyen en las decisiones de las personas. Thaler y SUnSTEIN (2008) p. 243. Con todo, de lo anterior no se sigue que no existan determinados que criterios que puedan promover más (o menos) la neutralidad. A modo de ejemplo puede señalarse la aleatoriedad de la información (piénsese en el orden de los candidatos en una papeleta de votación), la completitud de la información o el tratamiento igualitario de la información.

98 Allemano y Spina (2014) pp. 450 s.; Baldwin (2014) p. 836; Hansen y Jespersen (2013) pp. 26 s. En contra, WiLKINSON (2003) pp. 9-11.
} 
información debe ser accesible y comprensible. Esto significa que ella debe ser fácil de conseguir y fácil de interpretar, de manera que apoye o contribuya de forma adecuada, significativa y útil como apoyo, y no como obstáculo, a la formación de preferencias ${ }^{99}$.

(ii) Tratándose de las reglas por defecto la situación es más compleja puesto que ellas, tal como se indicó más arriba, inciden en las operaciones cognitivas regidas por el sistema 1 y tienden a ser adoptadas irreflexivamente por sus destinatarios. Por consiguiente, aspirar a que por sí solas produzcan efectos educativos y conduzcan a la adopción de decisiones más conscientes e informadas es poco realista. Sin embargo, un eventual criterio para establecer su compatibilidad con la libertad individual es dado por la posibilidad efectiva de excluirse de la aplicación de la regla por defecto (reglas de opt-out) y seleccionar otras alternativas. En este sentido, las demás alternativas disponibles deben ser conocibles y accesibles tanto desde un punto de vista material como económico ${ }^{100}$. Otro criterio podría decir relación con el nivel de complejidad técnica de la materia a la se refieren. Así, mientras mayor sea el nivel de complejidad y el grado de experticia requerido para tomar una decisión informada, más aconsejable pudiera ser el recurso a esta técnica. En tales contextos, las reglas por defecto pueden ser entendidas como un resguardo a la libertad individual, en la medida que ayudan a las personas a centrar su atención en los asuntos que más les importan. Si hubiera que escoger activamente en todo momento, requiriendo un considerable grado de conocimiento para tomar decisiones óptimas, la libertad podría hacerse ilusoria ${ }^{101}$.

(iii) Por lo que respecta a las advertencias gráficas o textuales, ellas también suelen ser vistas con recelo, toda vez que apelan a las emociones de las personas, potencialmente obstruyendo su racionalidad ${ }^{102}$. Con todo, las advertencias también transmiten información o dan prominencia a ciertas razones para cambiar el propio comportamiento y, por tanto, en alguna medida también apelan al sistema 2 de pensamiento ${ }^{103}$. Bajo este prisma, un primer criterio para juzgar su conformidad con la dignidad humana podría ser la confiabilidad y veracidad de la información en que se sustentan. En adición, podría considerarse el grado con que la medida reposa en las preferencias declaradas de las personas. Supóngase, por ejemplo, que se constatara que un elevado porcentaje de fumadores desea dejar de fumar y valora positivamente el uso de advertencias gráficas como técnica para ayudarles a cumplir su propósito. En tal evento, la medida difícilmente podría contar como un acto de manipulación, por más que explote los sesgos o apele a las emociones de sus destinatarios, en lugar de incentivar su reflexión consciente, pues no busca subvertir sus verdaderas preferencias ${ }^{104}$.

De surgir un cuestionamiento acerca del potencial lesivo de un nudge a la dignidad y la libertad, la distinción entre nudges educativos y no educativos puede ser relevante para conducir el juicio de necesidad, en el marco de la aplicación del test de proporcionalidad. Como es sabido, dicho juicio busca precisar dos cuestiones en relación con la medida so-

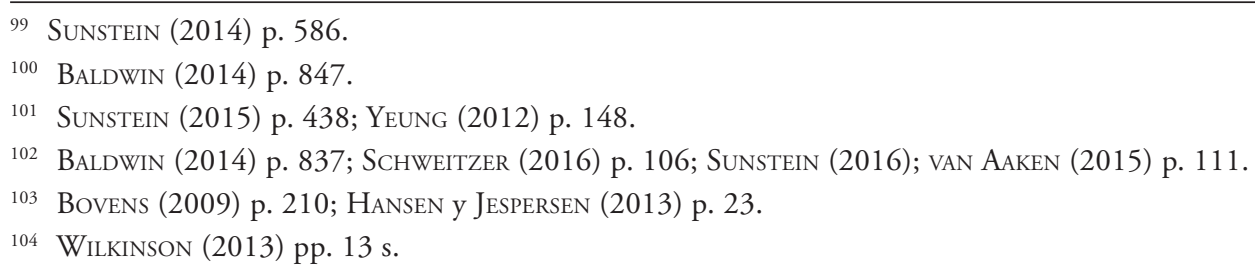


metida a control: primero, si existe otra medida alternativa que resulte igualmente eficaz que aquélla y, segundo, si dicha alternativa resulta menos restrictiva. Respecto de la primera cuestión, corresponderá a los expertos en ciencias conductuales pronunciarse acerca de la eficacia de la regulación conductualmente informada ${ }^{105}$. En cuanto a la segunda cuestión, en cambio, los criterios propuestos podrían servir como guía para comparar el nivel de restricción a la libertad individual que podría conllevar una regulación tradicional en contraste con un nudge o de un nudge educativo en contraste con uno no educativo.

Sin perjuicio de lo anterior, es importante aclarar que un nudge que no satisfaga los criterios recién propuestos -es decir, que no sea educativo- no necesariamente adolecerá de un vicio de inconstitucionalidad, aun cuando pudiera apreciarse como manipulador. Al igual que con toda otra medida estatal, el parámetro que permitirá en este caso juzgar la legitimidad del nudge será la proporcionalidad stricto sensu entre el grado de afectación de la libertad y la importancia de los fines que se logran con ella ${ }^{106}$. Es así como una afectación mínima de la libertad, como la que tendría lugar cuando se utilizan ilusiones ópticas para que los conductores manejen con más cautela, es proporcional a la importancia de los fines que se logran con ello: la disminución de accidentes de tránsito. En cambio, una campaña educativa sobre los riesgos de la obesidad que estigmatiza o ridiculiza los hábitos de alimentación de personas con sobrepeso o que las representa de forma degradante podría ser desproporcionada. Lo anterior sería especialmente cierto si, además, dicha campaña no considerara otros factores que pueden ser causas de obesidad tan o más gravitantes que las solas decisiones de consumo de las personas ${ }^{107}$.

\section{DEMOCRACIA, PUBLICIDAD Y TRANSPARENCIA}

Una primera proyección del principio de publicidad y transparencia al nudge apunta al procedimiento mediante el cual este es instituido. Este no debe ser secreto ni quedar reservado únicamente a expertos, sino que debe ofrecer garantías de representatividad y de deliberación pública. En este sentido, el proceso legislativo parece ser el mecanismo más idóneo al efecto, especialmente si la afectación a la libertad individual que representa el empleo de conocimientos propios de las ciencias conductuales es considerable ${ }^{108}$. Con ello no solo se asegura la participación popular y la transparencia y publicidad en el debate sobre su adopción; además, permite dar visibilidad a la medida misma y posibilita su impugnación. No obstante, como se precisó previamente, en los hechos es usual que el nudge se establezca a través de intervenciones estrictamente administrativas, como campañas educativas, establecimiento o modificación de reglas por defecto en plataformas digitales públicas, alteraciones al entorno físico, etc. ${ }^{109}$. De acuerdo con la literatura comparada sobre este

\footnotetext{
105 Precisamente en este punto, como lo sugiere alguna doctrina, es que el nudge podría no superar el test de proporcionalidad, toda vez que no existe evidencia empírica sólida respecto de su eficacia en comparación con las técnicas tradicionales de regulación. En este sentido, véase Allemano y Spina (2014) pp. 442 s.; McCRudden y King (2016) p. 130.

106 SChWeitzer (2016) pp. 110-112; VAN AAKen (2015) p. 122.

107 BALDWIN (2014) p. 839.

108 McCrudden y King (2016) pp. 123 s.

109 BALDWIN (2014) p. 845.
} 
punto, lo anterior puede resultar problemático toda vez que el origen administrativo de la medida se tiende a relacionar con la idea de informalidad y ausencia de control ${ }^{110}$.

Esa clase de observaciones no es del todo pertinente en su proyección al derecho chileno. De acuerdo con el art. $8^{\circ}$ inc. $2^{\circ} \mathrm{CPR}$ "[s]on públicos los actos y resoluciones de los órganos del Estado, así como sus fundamentos y los procedimientos que utilicen”. Es así como el solo origen administrativo de la regulación no la excluye del ámbito de cobertura del principio de publicidad y transparencia, en los términos previstos por la disposición antes citada. De ahí que la satisfacción de ese estándar sea un primer parámetro a considerar: el órgano en cuestión debe dar a conocer el contenido del nudge, su fundamento y el procedimiento empleado para su adopción. Ese es el estándar mínimo. Ahora bien, los órganos administrativos pueden ir más allá del estándar mínimo, tal como lo demuestra el caso de "Cuentas Claras, Simples y Transparentes" y adoptar medidas de publicidad adicionales. Justamente, tomando como referencia ese caso, dichas medidas pueden incluir el levantamiento de datos relativos a las preferencias de los destinatarios de la regulación, la realización de campañas de difusión, etc.

Por otro lado, el principio de publicidad y transparencia requiere que la medida misma sea "visible"111. Ergo, las señales sensoriales (auditivas, olfativas, visuales, etc.) por medio de las que se exterioriza el nudge también deben ser perceptibles, de tal manera que cualquier observador medianamente atento pueda apreciarlas como un intento deliberado de influir en sus decisiones ${ }^{112}$. Gracias a la perceptibilidad de las mentadas señales sensoriales, las personas deberían reconocer fácilmente la intención detrás de las mismas y, si lo desean, deberían poder resistirse activamente a seguir la conducta esperada ${ }^{113}$ o cuestionar su constitucionalidad ${ }^{114}$. No sería suficiente, entonces, un anuncio estatal genérico acerca del uso de técnicas regulatorias basadas en aportes de las ciencias conductuales para dirigir la conducta individual a fines vistos como socialmente deseables. Además, sería necesario que los destinatarios de estas medidas sean capaces de apreciar la manera en que el uso de dichos conocimientos pretende orientar su conducta, en un sentido u otro, incluso cuando ello pudiera disminuir la eficacia de dichas medidas ${ }^{115}$.

\footnotetext{
110 Allemano y Sina (2014) p. 432; Van Aaken (2015) p. 102.

111 VAN AAKen (2015) p. 110.

112 Hansen y Jespersen (2013) p. 21. Desde una perspectiva crítica, se sostiene un nudge visible sería menos intenso que un nudge invisible, precisamente porque se puede advertir, eludir e impugnar. Eso explica que alguna doctrina sostiene que la exigencia de visibilidad no es adecuada para esta clase de regulaciones, toda vez que disminuiría considerablemente su eficacia. En este sentido se ha sostenido que ciertos nudges "típicamente funcionan mejor en la oscuridad”. Bovens (2009) p. 210.

113 Hansen y Jespersen (2013) p. 21.

114 VAN AAKEN (2015) p. 110.

115 Baldwin (2014) p. 836; Bovens (2009) p. 216; Hausman y Welch (2010) p. 135.
} 


\section{CONCLUSIONES}

1. En los últimos diez años ha surgido un creciente interés en torno a la figura del nudge como técnica de orientación de las conductas humanas basada en los aportes de las ciencias conductuales. Según ellas, existirían dos sistemas de procesos cognitivos: uno sustentado en intuiciones, heurísticas y sesgos que simplifican los procesos de toma de decisiones (sistema 1) y otro que reposa en la lógica y la reflexión (sistema 2). Esta observación es relevante para el derecho porque permite a los reguladores comprender el comportamiento de las personas frente a ciertos estímulos o en determinados contextos e influir en el mismo. La presente investigación se ha centrado en el recurso estatal a esta figura, como alternativa a las formas tradicionales de regulación, con miras a identificar sus ámbitos de aplicación en el derecho chileno y sus potenciales problemas de constitucionalidad.

2. El ordenamiento jurídico chileno ofrece diversos ejemplos de regulaciones consistentes con la noción doctrinaria de nudge, pese a que esta última no tenga mayor desarrollo dogmático a nivel nacional ni se utilice esa precisa denominación. Así puede observarse en las áreas de la salud, del consumo de energía y del ahorro y la previsión social. Cabe advertir que, al efecto, las autoridades chilenas utilizan distintas técnicas que incluyen, principalmente, la provisión de información o disclosure, la fijación de reglas por defecto y la impresión de advertencias gráficas o textuales en los envases de productos cuyo consumo se considera riesgoso.

3. La literatura comparada sobre el tópico cuestiona recurrentemente la legitimidad del nudge en razón de su potencial lesivo a la dignidad humana y la libertad individual, por perseguir fines paternalistas y entrañar manipulación. De igual modo, se crítica su carácter tecnocrático e informal, así como la falta de transparencia en su proceso de diseño e implementación, en cuanto dificultaría o derechamente imposibilitaría el control del poder estatal. Mas, una mirada detenida a estas posturas críticas revela que las mismas no tienen un carácter absoluto o general, sino que se dirigen en específico a ciertos nudges. De ahí que a partir de dichas posturas críticas sea posible deducir determinados criterios que podrían revestir utilidad en el examen de su constitucionalidad.

4. Respecto de este último punto, un primer criterio de evaluación podría ser el que la medida persiga la consecución de fines de interés general y no puramente paternalistas. Otro criterio vendría dado por la medida en que el nudge contribuya a promover la libre adopción de decisiones racionales e informadas, en lugar de tan solo explotar las emociones y sesgos de las personas. Finalmente, un último criterio correspondería a la visibilidad del nudge, de modo que este sea perceptible y eventualmente sea posible su impugnación. En tales condiciones, el nudge podría estimarse compatible con la dignidad humana, la libertad individual, la democracia y el principio de publicidad y transparencia.

5. Todavía quedan muchas interrogantes por responder en torno al uso de nudges. Por ejemplo, ¡existen otros posibles ámbitos de afectación de derechos fundamentales o de bienes y valores constitucionales, distintos a los abordados en esta investigación, derivados de la implementación esta clase de regulaciones? ¿Cómo incidiría en las premisas básicas sobre las que reposa el constitucionalismo contemporáneo un uso masivo de aquéllas? ¿Cuál es el tratamiento constitucional que se debe dar a las consecuencias imprevistas de los nud- 
ges impuestos por el Estado? El marco analítico aquí desarrollado puede servir de base para responder, al menos parcialmente, estas y otras interrogantes. En este contexto, la presente investigación puede ser vista como un primer "empujoncito" en orden al desarrollo dogmático y de criterios de evaluación de las herramientas regulatorias conductualmente informadas.

\section{BIBLIOGRAFÍA CITADA}

Aldunate Lizana, Eduardo (2008): Derechos Fundamentales (Santiago, Thomson-Reuters). Alemanno, Alberto y Spina, Alessandro (2014): "Nudging legally: On the checks and balances of behavioral regulation", en International Journal of Constitutional Law, vol. 12, No 2: pp. 429-456.

Arnold, Rainer, Martínez Estay, José Ignacio, ZúÑiga Urbina, Francisco (2012): “El principio de proporcionalidad en la jurisprudencia del Tribunal Constitucional”, Estudios Constitucionales, vol. 10, No 1: pp. 65-116.

Baldwin, Robert (2014): "From Regulation to Behaviour Change: Giving Nudge the Third Degree", Modern Law Review, vol. 77, No 6: pp. 831-857.

Barr, Michael S. (2012): "Behaviorally Informed Regulation”, en Mullainathan, Sendhil y SHAfir, Eldar (eds.), Behavioral Foundations of Public Policy (Princeton, Princeton University Press) pp. 440-464.

Barr, Michael S., Mullainathan, Sendhil y Shafir, Eldar (2009): “The Case for Behaviorally Informed Regulation”, en Moss, David y Cisternino, John (eds.), New Perspectives on Regulation (Cambridge, The Tobin Project) pp. 25-61.

Berlin, Isaiah (2013): “Two Concepts of Liberty”, en Hardy, Henry (ed.), Liberty (Oxford, Oxford University Press) pp. 166-217.

Bovens, Luc (2009): “The Ethics of Nudge”, en Grüne-Yanoff, Till y Hansson, Sven Ove (eds.), Preference Change: Approaches from Philosophy, Economics and Psychology (Dodrecht, Springer) pp. 207-219.

Brownsword, Roger (2008): "So What Does the World Need Now? Reflections on Regulating Technologies”, en Brownsword, Roger y YeunG, Karen (eds.), Regulating technologies: legal futures, regulatory frames and technological fixes (Oxford, Hart Publishing) pp. 23-48.

Brownsword, Roger (2014): "Human Dignity, Human Rights, and Simply Trying to Do the Right Thing", en McCrudden, Christopher (ed.), Understanding Human Dignity (Oxford, Oxford University Press) pp. 345-358.

Cassesse, Sabino (2016): "Exploring the Legitimacy of Nudging”, en Kemmerer, Alexandra et al. (eds.), Choice Architecture in Democracies: Exploring the Legitimacy of Nudging (Oxford, Hart Publishing) pp. 241-245.

Contesse Singh, Jorge (2017): "Proporcionalidad y derechos fundamentales", en Contreras, Pablo y Salgado, Constanza (eds.), Manual sobre derechos fundamentales: Teoría general (Santiago, LOM Ediciones) pp. 285-322.

Covarrubias, Ignacio (2014): “¿Emplea el Tribunal Constitucional el test de proporcionalidad?”, Estudios Constitucionales, vol. 12, No 1: pp. 163-237. 
Díaz García, Iván L. (2011): “Aplicación del principio de proporcionalidad en orden a juzgar sobre la licitud o ilicitud de una restricción a derechos fundamentales", Revista de Derecho de la Pontificia Universidad Católica de Valparaíso, vol. 36: pp. 167-206.

Dworkin, Ronald (2011): Justice for Hedgehogs (Cambridge, The Belknap Press of Harvard University Press).

Goodwin, Morag (2016): "Architecture, Choice Architecture and Dignity", en Kemmerer, Alexandra et al. (eds.), Choice Architecture in Democracies: Exploring the Legitimacy of Nudging (Oxford, Hart Publishing) pp. 285-308.

Hansen, Pelle Guldborg y Jespersen, Andreas Maaløe (2013): "Nudge and the Manipulation of Choice: A Framework for the Responsible Use of the Nudge Approach to Behaviour Change in Public Policy", European Journal of Risk Regulation, vol. 4, No 1: pp. 3-28.

Hausman, Daniel M. y Welch, Brynn (2010): “Debate: To Nudge or Not to Nudge”, en The Journal of Political Philosophy, vol. 18, No 1: pp. 123-136.

Husak, Douglas (2015): "Paternalism", en Marmor, Andrei (ed.), The Routledge Companion to Philosophy of Law (New York, Routledge) pp. 467-480.

John, Peter y STOKer, Gerry (2017): "From nudge to nudge plus: behavioural public policy for a self-guiding society”. Disponible en: http://www.governanceinstitute.edu.au/ magma/media/upload/ckeditor/files/From \%20nudge\%20to\%20nudge $\% 20$ plus $\% 20$ behavioural\%20public\%20policy\%20for\%20a\%20self-guiding\%20society.pdf. Fecha de consulta: 25 de junio de 2018.

Jolls, Christine, Sunstein, Cass R. (2006): “Debiasing through Law”, Journal of Legal Studies, vol. 35, No 1: pp. 199-242.

Jolls, Christine, Sunstein, Cass R. y Thaler, Richard (1998): "A Behavioural Approach to Law and Economics", Stanford Law Review, vol. 50: pp. 1471-1550.

Kahneman, David (2011): Thinking Fast and Slow (New York, Macmillan).

KallbeKKEN, Steffen y SÆLEN, Håkon (2013): “'Nudging' hotel guests to reduce food waste as a win-win environmental measure”, Economics Letters, vol. 119: pp. 325-327.

KANT, Immanuel (2002): Groundwork for the metaphysics of moral (New Haven and London, Yale University Press).

Lombardini, Chiara y Lankoski, Leena (2013): "Forced Choice Restriction in Promoting Sustainable Food Consumption: Intended and Unintended Effects of the Mandatory Vegetarian Day in Helsinki Schools”, Journal of Consumer Policy, vol. 36: pp. 159-178.

McCrudden, Christopher y King, Jeff (2016): “The Dark Side of Nudging: The Ethics, Political Economy, and Law of Libertarian Paternalism”, en Kemmerer, Alexandra et al. (eds.), Choice Architecture in Democracies: Exploring the Legitimacy of Nudging (Oxford, Hart Publishing) pp. 67-132.

Mill, John Stuart (2001): On Liberty (Kitchener, Batoche Books).

Nogueira Alcalá, Humberto (2010): "Dignidad de la persona, derechos fundamentales y bloque constitucional de derechos: una aproximación desde Chile y América Latina”, Revista de Derecho, vol. 5: pp. 79-142.

Nogueira Alcalá, Humberto (2003): Teoría y dogmática de los derechos fundamentales (México D.F., UNAM). 
Nogueira Alcalá, Humberto (2002): "La libertad personal y las dos caras de Jano en el ordenamiento jurídico chileno", Revista de Derecho (Valdivia), vol. XIII: pp. 161-186.

Pardo Vergara, Soledad (2013): "El derecho de libertad general en Chile", en Bassa MerCADO, Jaime (ed.), Los desafios de la interpretación constitucional. Protección de derechos fundamentales, control de constitucionalidad, enseñanza del derecho (Valparaíso, Edeval) pp. 183-234.

PAYne, Colin R. et al. (2016): “This way to produce: Strategic use of arrows on grocery floors facilitate produce spending without increasing shopper budgets", Journal of $\mathrm{Nu}$ trition Education and Behavior, vol. 48, No 7: pp. 512-513.

Petit, Philip (2012): On the People's Terms: A Republican Theory and Model of Democracy (Cambridge, Cambridge University Press).

Raz, Joseph (1988): The Morality of Freedom (Oxford, Oxford University Press).

Schmidt, Andreas T. (2017): "The Power to Nudge", American Political Science Review, vol. 111, No 2: pp. 404-417.

Schultz, P. Wesley et al. (2007): “The Constructive, Destructive, and Reconstructive Power of Social Norms", Psychological Science, vol. 18: pp. 429-434.

SCHWEIZER, Mark (2016): "Nudging and the Principle of Proportionality: Obliged to Nudge?”, en Mathis, Klaus y Tor, Avishalom (eds.), Nudging: Possibilities, Limitations and Applications in European Law and Economics (Dodrecht, Springer) pp. 93-119.

Scoccia, Danny (2018): “The Concept of Paternalism”, en Grill, Kalle y Hanna, Jason (eds.), The Routledge Handbook of the Philosophy of Paternalism (New York, Routledge) pp. 11-23.

Sharot, Tali (2011): The Optimism Bias: A Tour of the Irrationally Positive Brain (New York, Pantheon Books).

STroeker, Natasha Els (2016): "An overview of behavioral economics in Dutch policy making. The next step: how to nudge policy makers", APSTRACT, vol. 10, No 2-3: pp. 27-32.

Sunstein, Cass R. (2016): "People Prefer System 2 Nudges (Kind of)", Duke Law Journal, vol. 66, No 1: pp. 121-168.

Sunstein, Cass R. (2015): “The Ethics of Nudging”, Yale Journal of Regulation, vol. 32, No 2: pp. 414-450.

Sunstein, Cass R. (2014): "Nudging: A Very Short Guide", Journal of Consumer Policy, VOL. 37, No 4: pp. 583-588.

Sunstein, Cass R. (2013a): Simpler: The Future of Government (New York, Simon \& Schuster).

Sunstein, Cass R. (2013b): "The Storrs Lectures: Behavioral Economics and Paternalism”, The Yale Law Journal, vol. 122, No 7: pp. 1826-1899.

Thaler, Richard H. y Sunstein, Cass R. (2008) Nudge: Improving Decisions about Health, Wealth, and Hapiness (New Haven, Yale University Press).

Thomas, Matthew y Buckmaster, Luke (2010): Paternalism in Social Policy: When is it Justifiable? (Canberra, Parliament of Australia).

Tversky, Amos y Kahneman, David (1974): “Judgment under Uncertainty: Heuristics and Biases”, Science, vol. 185, No 4157: pp. 1124-1131.

VAn AAKEN, Anne (2015): "Judge the Nudge: In Search of the Legal Limits of Paternalistic Nudging in the EU”, en Alemanno, Alberto y Sibony, Anne-Lise (eds.), Nudge and the Law, A European Perspective (Oxford, Bloomsbury) pp. 100-136. 
Vivanco Martínez, Ángela (2006): Curso de derecho constitucional. Aspectos dogmáticos de la Carta Fundamental de 1980, Tomo II (Santiago, Ediciones Universidad Católica de Chile).

Waldron, Jeremy (2014): "It's all for your own good", The New York Review of Books, 23 de octubre.

Wilkinson, T.M. (2013): "Nudging and Manipulation”, Political Studies, vol. 61: pp. 341-355.

Wood, Allen W. (2014): “Coercion, Manipulation, Exploitation”, en Coons, Christian y Weber, Michael (eds.), Manipulation: Theory and Practice (Oxford, Oxford University Press) pp. 17-50.

Yeung, Karen (2012): "Nudge as Fudge", The Modern Law Review, vol. 75, No 1: pp. 122-148.

Yeung, Karen (2011): "Can We Employ Design-Based Regulation While Avoiding Brave New World?", Law, Innovation and Technology, vol 3, No 1: pp. 1-29.

Yeung, Karen (2008): "Towards an Understanding of Regulation by Design", en BrownSWORD, Roger y YeUnG, Karen (eds.), Regulating technologies: legal futures, regulatory frames and technological fixes (Oxford, Hart Publishing) pp. 79-108.

ZúNIGA F., Alejandra (2015): "El consentimiento presunto y la reciprocidad como mecanismos para aumentar la donación de órganos”, Revista Médica Chile, vol. 143, No 10: pp. 1331-1336.

\section{DOCUMENTOS OFICIALES}

Laboratorio de Gobierno, SERNAC y SEC (2017): "La co-creación de las nuevas cuentas de electricidad". Disponible en: http://lab.gob.cl/uploads/filer_public/2a/df/2adfb64b2220-4764-b5c2-c6efdd8c630b/proyecto_cuentas_claras.pdf. Fecha de consulta: 11 de junio de 2018.

Ministerio de Energía (2014): “Agenda de Energía: un desafío país, progreso para todos”. Disponible en: http://www.energia.gob.cl/sites/default/files/agenda_de_energia_version_completa_esp.pdf. Fecha de consulta: 11 de junio de 2018.

OECD (2017): Behavioural Insights and Public Policy: Lessons from Around the World (Paris, OECD Publishing). Disponible en: https://people.kth.se/_gryne/papers/OECD_2017. pdf. Fecha de consulta: 2 de junio de 2018.

\section{NORMAS CITADAS}

Constitución Política de la República de Chile (22/9/2005).

LEY No 19.419 (9/10/1995), regula actividades que indica relacionadas con el tabaco.

LEY No 19.451 (10/10/1996), establece normas sobre trasplante y donación de órganos.

LEY No 20.255 (17/3/2008), establece reforma previsional.

LEY No 20.413 (15/1/2010), modifica la Ley $N^{\circ} 19.451$, con el fin de determinar quienes pueden ser considerados donantes de órganos y la forma en que pueden manifestar su voluntad.

LEY No 20.606 (6/7/2012), sobre composición nutricional de los alimentos y su publicidad. 
LEY No 20.673 (7/6/2013), modifica la Ley No 19.451 respecto a la determinación de quiénes pueden ser considerados donantes de órganos.

LEY No 20.894 (26/1/2016), prorroga la obligatoriedad de cotizar de los trabajadores independientes y adecúa normativa previsional que indica.

Proyecto de ley sobre Regulación de alimentos poco saludables (Boletín Nº 4.921-11).

\section{JURISPRUDENCIA CITADA}

REQUERIMIENTO DE INAPLICABILIDAD POR INCONSTITUCIONALIDAD PRESENTADO POR LA CORTE DE Apelaciones de Santiago respecto del artículo 102 del Código CiVIL, en los aUtos Rol No 6787-2010, SOBRE RECURSO DE PROTECCIÓN INTERPUESTO ANTE LA CORTE DE APELACIONES de Santiago en contra de Oficial de Registro Civil (2011): Tribunal Constitucional chileno, Rol No 1881, de tres de noviembre de 2011.

REQUERIMIENTO DE INAPLICABILIDAD POR INCONSTITUCIONALIDAD PRESENTADO POR JORGE WASHington Sepúlveda Álvarez respecto del artículo 365 del Código Penal, en la causa RIT $N^{\circ}$ 1287-2008, RUC $N^{\circ}$ 0800242317-1, SEGUIDA ANTE EL JUZGADO DE GARANTÍA DE CANETE (2011): Tribunal Constitucional chileno, Rol No 1683, de cuatro de enero de 2011. 